\title{
VATS or simple talc poudrage under medical thoracoscopy for recurrent spontaneous pneumothorax
}

\section{To the Editors:,}

We read with interest the paper by RENA et al. [1] published recently in the European Respiratory Journal. The authors compared two surgical techniques of pleurodesis (i.e., mechanical abrasion and apical pleurectomy). They deliberately selected patients with stage III primary spontaneous pneumothorax (PSP), according to Vanderschueren classification, and showed that mechanical pleural abrasion requiring less time to be performed was safer than apical pleurectomy. It was a well-designed randomised controlled study answering an editorial [2] encouraging more scientific evaluation of videoassisted thoracic surgery (VATS).

However, such a study raises two questions. First, we are not sure that the Vanderschueren classification is still up to date to make therapeutic decisions about treatment of recurring PSP. PSP is a diffuse disease of the pleura as recently and elegantly shown by NOPPEN et al. [3]. We agree that the pathophysiology of PSP remains poorly understood but we have enough data showing that blebs and bullae, or size of blebs or bullae, are not a real risk factor for PSP as restated by RENA et al. [1]. The staging of PSP, as classified by Vanderschueren by looking macroscopically at the visceral pleura, implies some continuum in the process of PSP development. This implies that the higher the stage of PSP, the greater the risk of relapse in case PSP. Such a concept has never been proven at all after more than 25 years [4]. Secondly, VATS using these two techniques of pleurodesis has the same long-term recurrence rate of pneumothorax (i.e. about 5\%) as medical thoracosocopy with talc poudrage, as shown in another randomised controlled trial [5]. Medical thoracoscopy is a simple and minimally invasive technique, performed under local anesthesia in a simple endoscopy suite, which does not require general anesthesia and double lumen tube intubation, making this technique much more cost-effective; with a cost of about a third of VATS, as suggested by SCHRAMEL et al. [6]. RENA et al. [1] did not consider talc as an appropriate pleurodesis agent to prevent recurrence of pneumothorax. Such an assertion is based on guidelines and not on real scientific evidence. For a century, the talc used in Western Europe has been shown to be safe in many thousands of patients [7], contrary to the talc currently used in the UK or USA. European talc is safe and is the best sclerosing agent currently available to produce pleurodesis, as shown experimentally [8]. It does not produce systemic dissemination of particles, contrary to the talc used in American studies [9]. It has recently been shown to be well tolerated in a large European prospective study involving patients in much worse condition of health than PSP as they suffered from pleural involvement of metastatic malignant tumours [10].Using large-particle talc, poudrage under thoracoscopy is a safe and cost-effective procedure to prevent relapse of
PSP, as demonstrated by the most extensive studies on pneumothorax management to date [11, 12]. The need for a phase III randomised study comparing surgical pleurodesis and thoracoscopy talc pleurodesis is warranted to definitively select the best management of recurrent spontaneous pneumothorax.

\section{J-M. Tschopp*, J-M. Schnyder, M. Froudarakis" and P. Astoul ${ }^{\top}$}

*Centre Valaisan de Pneumologie, Montana, Switzerland, "Dept of Pneumonology, Democritus University of Thrace Medical School, Alexandroupolis, Greece, and "Dept of Thoracic Oncology, Hôpital Sainte-Marguerite, Marseille, France.

\section{STATEMENT OF INTEREST}

None declared.

\section{REFERENCES}

1 Rena O, Massera F, Papalia E, Della Pona C, Robustellini M, Casadio C. Surgical pleurodesis for Vanderschueren's stage III primary spontaneous pneumothorax. Eur Respir J 2008; 31: 837-841.

2 LoCicero J 3rd, Video-assisted thoracoscopy's anniversary. Chest 1997; 111: 268-269.

3 Noppen M, Dekeukeleire T, Hanon S, et al. Fluoresceinenhanced autofluorescence thoracoscopy in patients with primary spontaneous pneumothorax and normal subjects. Am J Respir Crit Care Med 2006; 174: 26-30.

4 Vanderschueren RG. Le talcage pleural dans le pneumothorax spontané. [Pleural talcage in patients with spontaneous pneumothorax (author's transl)]. Poumon Coeur 1981; 37: 273-276.

5 Tschopp JM, Boutin C, Astoul P, et al. Talcage by medical thoracoscopy for primary spontaneous pneumothorax is more cost-effective than drainage: a randomised study. Eur Respir J 2002; 20: 1003-1009.

6 Schramel FM, Sutedja TG, Braber JC, van Mourik JC, Postmus PE. Cost-effectiveness of video-assisted thoracoscopic surgery versus conservative treatment for first time or recurrent spontaneous pneumothorax. Eur Respir J 1996; 9: 1821-1825.

7 Boutin C, Viallat JR, Aelony Y, eds. Pratical Thoracoscopy. Berlin, Springer-Verlag, 1991.

8 Bresticker MA, Oba J, LoCicero J 3rd, Greene R., Optimal pleurodesis: a comparison study. Ann Thorac Surg 1993; 55: 364-366.

9 Fraticelli A, Robaglia-Schlupp A, Riera H, MonjanelMouterde S, Cau P, Astoul P. Distribution of calibrated 
talc after intrapleural administration: an experimental study in rats. Chest 2002; 122: 1737-1741.

10 Janssen JP, Collier G, Astoul P, et al. Safety of pleurodesis with talc poudrage in malignant pleural effusion: a prospective cohort study. Lancet 2007; 369: 1535-1539.

11 Weissberg D, Refaely Y. Pneumothorax. Experience with 1,199 patients. Chest 2000; 117: 1279-1285.
12 Cardillo G, Carleo F, Giunti R, et al. Videothoracoscopic talc poudrage in primary spontaneous pneumothorax: a single-institution experience in 861 cases. J Thorac Cardiovasc Surg 2006; 131: 322-328.

\section{Methodological issues in therapeutic trials of COPD}

\section{To the Editors:}

I read with great interest the paper by SuISSA et al. [1], which has shed some light on the pitfalls when evaluating the effects of inhaled corticosteroids (ICS) on chronic obstructive pulmonary disease exacerbations. Indeed, they conclude, "various methodological shortcomings ...the effectiveness of inhaled corticosteroids in treating chronic obstructive pulmonary disease remains doubtful" [1]. The controversy about the role of ICS in COPD exacerbations is becoming even more complex, with the VIVACE [2] study reporting that pneumonia is associated with ICS use in COPD, a possible effect also reported in several more recent studies [3-5]. Moreover, the considerable cost of ICS treatment should also be taken into account. Several other issues have been raised AARON et al. [6] and some, but not all, of the aspects were already reflected [7].

The observed differences between former ICS users and ICS naïve COPD patients in the OPTIMAL trial [1] is impressive but may not be generalised. In other trials this effect is much less remarkable and does not reach clinical relevance. In a post hoc analysis we have examined the ICS effect on exacerbations in former ICS, long-acting $\beta$-agonists and combination product users and nonusers in the VIVACE study [2]. VIVACE was a 1yr trial in which salmeterol was compared with salmeterol/ fluticasone. Irrespective of former ICS use, we observed that patients benefited from additional ICS treatment compared with salmeterol alone. Indeed, the benefit in former ICS users appeared greater (table 1). However, our post hoc analysis shows that the ICS effect in VIVACE is exclusively attributable neither to current bronchodilator therapy nor to former ICS use. Thus the common clinical practice of initiating ICS treatment in COPD patients with frequent exacerbations remains advisable.

Time to first exacerbation was analysed by the Cox proportional hazard model with the following predictive variables: treatment; sex; age; smoking status; forced expiratory volume in one second ( $\%$ predicted at the start of randomised treatment period); and long-acting $\beta$-adrenergic use pre-study. The frequency of exacerbations was analysed using a Poisson regression model with the same covariables as for time to first exacerbation.

The classical intention to treat analysis is helpful in assessing, conservatively, the effect of an intervention and also prevents bias from the regression artifact particularly in a study population with differential (not at random) dropout rates. Conversely, however, from a clinical point of view, in a 3-yr pharmacological trial such as TORCH [3] one expects to measure the effect of a current (continuing) treatment on an outcome. An intention-to-treat analysis will assume that, at the

TABLE 1 Treatment effect (salmeterol relative to salmeterol/fluticasone) according to pre-trial inhaled corticosteroid (ICS) use

HR: hazard ratio; Cl: confidence interval; RR: ratio rate. Values more than one indicate a higher rate for salmeterol relative to salmeterol/fluticasone treatment. Time to first exacerbation was analysed by Cox's proportional hazard model with the following predictive variables: treatment, sex, age, smoking status, forced expiratory volume in one second (\% predicted at start of randomised treatment period) and long-acting $\beta$-adrenergic use pre-study. Count of exacerbation was analysed by use of a Poisson regression model with the same covariables as for time to first exacerbation. 